\title{
SESERAHAN DALAM PERKAWINAN MASYARAKAT ADAT LAMPUNG
}

\author{
Agung Tri Nugroho \\ Agungtri0011@gmail.com \\ Institut Agama Islam Agus Salim Metro Lampung
}

\begin{abstract}
Delivery or delivery money is money given by the male to the prospective in-laws for marital needs with its positive and negative impacts. The negative impact of delivery money is seen when it is set at a high amount by the prospective in-laws to be paid, making it difficult to be met. Not a few also couples who want to establish a household are forced to postpone marriage because of the high amount of money that has been determined from the woman side. The research question in this paper is how the implementation of the practice of conducting delivery money in marriage customs in Lampung, is it true that the determination of very high sums of money influences the delay in marriage in the community and how the Islamic law views the delivery money which causes delays in marriage. By using field research methods, the data have been grouped into two forms, namely quantitative data and qualitative data. Quantitative data is the data of the results of the questionnaire while the qualitative data is the data of the results of interviews and observations. Then from the quantitative data tables are then analyzed and concluded while the qualitative data is connected between one fact and the other facts, then analyzed using a descriptive analysis approach. The results of the study found that the indigenous people of Lampung all practiced giving money and stipulated it by looking at the education of women, their work and the number of stipulated habits in the village, and eight pending marriages from several cases due to high cash, to the impacts arising from the stipulation of high and contradictory money with valid 'urf terms; it can be concluded that the law of high passing money is not appropriate as it should apply. And many have charged men whose economies are middle to lower and who have dependents to carry out marriages resulting in delays in marriage.
\end{abstract}

Key words: Delivery money, Traditional marriage, Lampung, Seserahan.

\section{Pendahuluan}

Di dalam adat masyarakat Lampung, praktik perkawinan mengenal adanya sistem perkawinan yang menjadikannya berbeda dari masyarakat suku lain yang berada di Nusantara. Berbagai macam sistem pernikahan masyarakat Lampung pada saat ini dapat kita kelompokkan menjadi dua. Pertama, perkawinan yang melalui proses lamaran yang dapat dilakukan dalam bentuk upacara adat besar (gawei balak) atau upacara adat yang sederhana (gawei lunik); kedua, perkawinan yang dilakukan tanpa melalui proses lamaran yang dikenal dengan nama larian atau sebambangan terdapat budaya kawin lari yang masih dilakukan pada saat ini (Saputra, 2010: 2).

Budaya larian atau ngakuk mulei merupakan perkawinan yang dilakukan oleh seorang meghanai (bujang laki-laki) dan seorang mulei (gadis) di mana sang meghanai membawa lari terlebih dahulu si mulei sebelum adanya akad nikah. Dalam larian keluarga pihak gadis tidak 
mengetahui atau tidak dibicarakan terlebih dahulu. Praktik larian dalam masyarakat Lampung dilakukan dengan cara sebagai berikut.

1). Mulei yang dilarikan oleh meghanai, menaruh surat yang ditulis dan ditanda tangani oleh mulei itu sendiri. Isi surat tersebut menerangkan nama meghanai, asal kampung meghanai serta meninggalkan uang.

2). Apabila meghanai berasal dari kelompok Pepadun, meghanai akan membicarakan kepada keluarganya serta mengundang pemangku adat untuk bermusyawarah (ngukhaw muakhian). Keluarga si meghanai meminta maaf atas kesalahan karena keluarga meghanai tidak memberitahukan sebelumya.

3). Apabila meghanai tidak berasal dari kelompok Pepadun Lampung maka ngukhaw muakhian tidak wajib dilaksanakan. Selain itu keluarga meghanai pun wajib menyelesaikan masalah atau melaksanakan acara ngantak salah (meminta maaf kepada keluarga pihak mulei).

4). Praktik yang terjadi di dalam masyarakat, setelah proses diatas telah dilaksanakan, maka perkawinan dengan segera dilaksanakan.

Hadikusuma menyatakan latar belakang terjadinya sebambangan (praktik larian) antara laki-laki dan perempuan untuk maksud pernikahan, antara lain sebagai berikut (Angkupi, 2015).

1). Syarat-syarat pembayaran, pembiayaan, dan upacara perkawinan yang diminta pihak gadis tidak dapat dipenuhi pihak bujang.

2). $\mathrm{Si}$ gadis belum diizinkan orangtuanya untuk bersuami, sehingga akhirnya si gadis memutuskan untuk bertindak sendiri.

Fenomena larian merupakan bentuk ritual proses perkawinan yang dilakukan tanpa izin keluarga kedua belah pihak sebelumya. Secara filosofi praktik tersebut dilakukan karena biaya lamaran perkawinan masyarakat Lampung sangatlah tinggi. Jika menggunakan ritual proses lamaran, meghanai wajib memberikan seserahan serta uang yang jumlahnya ditetapkan sangat besar oleh pihak keluarga mulei. Oleh karena itu meghanai melakukan inisiatif dengan cara kawin lari. Larian pada awalnya hanya untuk menjembatani antara dua orang laki-laki dan perempuan yang memang saling cinta tetapi mereka tidak memiliki dana yang cukup untuk menyelenggaraan sebuah pesta pernikahan. Permasalahan yang terjadi saat ini adalah praktik larian sebagian besar telah disalahgunakan oleh para meghanai. Fakta yang terjadi dalam masyarakat Lampung saat ini adalah sebagai berikut.

1). Larian dilakukan tanpa pertimbangan terlebih dahulu. Meghanai melakukan larian hanya karena ingin cepat menikah, keluarga meghanai adakalanya tidak tahu, tetapi karena terlanjur sudah melarikan mulei, maka perkawinan terpaksa dilakukan.

2). Sebaliknya banyak dari keluarga mulei yang anak gadisnya dilarikan tidak setuju, tetapi karena terlanjur dilarikan maka terpaksa keluarga mulei menerima. Hal demikian terjadi ketika keluarga meghanai telah melakukan undur senato (Angkupi, 2015).

3). Terdapat anggapan masyarakat bahwa mulei (gadis) yang telah melakukan 
larian sudah dianggap janda dalam adat, oleh karena itu jika keluarga menolak perkawinan, keluarga mulei akan malu karena anak gadisnya sudah mengalami "aib" (tidak ada yang mau mengawini), oleh karena itu anak gadisnya harus segera dikawinkan.

4). Larian banyak dilakukan oleh pasangan yang masih usia sekolah, hal ini karena tidak dilakukan dengan persetujuan orang tua, sehingga banyak pasangan yang terpaksa kawin muda dan putus sekolah.

5). Pada kasus yang lebih ekstrim banyak larian yang dilakukan meghanai bahkan tanpa persetujuan mulei. Mulei diajak pergi dan tidak dipulangkan ke rumahnya. Mulei terpaksa menerimanya karena tidak mungkin menolak, jika menolak maka tidak ada yang akan mau mengawini mulei karena sudah dianggap ternodai. Kasus seperti ini dapat memenuhi unsur tindak pidana penculikan dan pelanggaran hukum perkawinan dalam hukum positif.

6). Pihak dari keluarga wanita yang tidak setuju untuk pernikahan tersebut, maka pihak keluarganya akan berusaha untuk mengambil wanita tadi dari tangan lakilakinya. Namun menurut adat yang berlaku di Lampung, wanita yang sudah dilarikan tidak dapat dikembalikan lagi kepada keluarga perempuan. Pihak keluarga lakilaki akan mempertahankan wanita tersebut demi kehormatan adat. Jika seorang mulei (perempuan) tidak mencintai seorang lakilaki, namun laki-laki tersebut membawa lari dia, biasanya trik yang digunakan oleh lakilaki adalah dengan menjanjikan akan membawanya jalan-jalan keliling kota tetapi setelah itu dibawa ke rumah pihak laki-laki.
Ketika keluarga dari perempuan hendak menjemput sang perempuan, pihak laki-laki akan mempertahankan perempuan tersebut supaya tidak bisa meninggalkan rumah lakilaki tersebut. Lebih baik mati daripada harus menanggung malu, itulah semboyan pihak keluarga laki-laki, sehingga wanita tersebut harus mengiyakan dari pada keluarganya jadi korban penganiayaan di rumah laki-laki tersebut.

7). Larian dianggap oleh kaum remaja sebagai trend dan ikut-ikutan, sehingga merusak masa depan remaja usia sekolah. Hal ini merupakan salah satu faktor penyebab tingginya tingkat kejahatan remaja di Provinsi Lampung.

Bentuk perkawinan larian pada dasarnya tidak layak untuk dilaksanakan dengan kondisi sosial masyarakat Lampung saat ini, karena telah terjadi perubahan makna, larian yang berubah menjadi pelanggaran hukum dan pelanggaran hakhak konstitusi wanita. Larian saat ini kehilangan nilai filosofinya, sebagian besar masyarakat Lampung kurang nyaman dengan proses perkawinam larian, yang hanya dimanfaatkan oleh orang-orang yang ingin mengambil jalan pintas untuk mendapatkan wanita.

Kondisi tersebut diperburuk oleh munculnya Pasal 16, Perda Tentang Pemeliharaan Kebudayaan Lampung yang kemudian dijadikan dasar hukum oleh orang-orang yang merasa diuntungkannya. Hal tersebut dapat dilihat dalam Perda yang justru mengatur bahwa Adat Budaya Lampung yang berkenaan dengan perkawinan adat, keberadaannya wajib dijaga, dipelihara dan dikembangkan (Pasal 16, 2008). Perda yang justru mengabsahkan 
hal-hal yang diresahkan masyarakat, yang sesungguhnya layak untuk dikaji ulang asas kemanfaatannya. Banyak permasalahan terjadi seperti permasalahan konflik masyarakat dan pelanggaran pidana karena melibatkan anak di bawah umur (Saputra, 2010: 8).

\section{Pengertian Seserahan dalam Praktik Perkawinan Masyarakat Lampung} Seserahan atau hantaran menurut Kamus Besar Bahasa Indonesia berasal dari perkataan "antaran" yang bermaksud uang sebagai pemberian dari pihak laki-laki kepada calon mertua (Kebudayaan, 1990). Pada zaman dahulu "antaran" diartikan oleh masyarakat yang beragama Hindu sebagai penjualan gadis kepada laki-laki. Manakala pada masa sekarang "antaran" mengalami perselisihan makna yang bermaksud adalah hadiah perkawinan untuk calon istri (Jafizham, 2010: 202).

Praktek uang hantaran tidak hanya berlaku di Lampung tetapi turut dipraktekkan oleh kaum Muslim di Indonesia. Dikarenakan faktor perbedaan bahasa, ras, suku dan kelompok masyarakat, maka istilah yang digunakan pun bervariasi. Masyarakat Bugis Makassar menggunakan istilah "uang panai" bagi uang hantaran dan bagi masyarakat Bugis di Jambi menggunakan istilah "doi nmenre" sedangkan masyarakat Aceh menggunakan istilah "uang hangus." Meskipun berbeda cara pelaksanaan yang disesuaikan menurut adat dan budaya masyarakat setempat tetapi maksudnya adalah sama sebagai maksud hadiah atau pemberian dalam acara pernikahan.

\section{Pandangan Tokoh Tentang Hukum Adat dalam Perkawinan Masyarakat Lampung}

Pandangan tentang Hukum Adat dalam persoalan perkawinan bisa merupakan urusan kerabat, persekutuan, martabat, bisa merupakan urusan pribadi, bergantung kepada tata susunan masyarakat yang bersangkutan. Perkawinan merupakan sarana dalam melangsungkan hidup kelompok masyarakat adat secara tertib dan teratur serta dapat pula dilakukan untuk mempertahankan gengsi atau martabat kelas di dalam dan di luar persekutuan (Sudiyat, 1981: 107-108). Walaupun perkawinan dapat dikatakan sebagai urusan keluarga, urusan kerabat, dan urusan masyarakat, pada dasarnya perkawinan tetap urusan hidup perseorangan juga dari pada pihak-pihak perseorangan yang kebetulan bersangkutan dengan itu. Proses perkawinan yang berjalan terutama dalam bentuk perkawinan lari bersama (vluchthuwelijk) dan perkawinan bawa lari (schaakhuwelijk) yang mencerminkan ketegangan antara golongan masyarakat dan manusia sebagai perseorangan (Pesponoto, 2013: 160). Perkawinan masih selalu diliputi hukum adat sebagai hukum rakyat yang hidup dan tidak tertulis dalam perundang-undangan Negara (Hazairin, 1975: 5).

Nani Soewondo (1984) menegaskan bahwa dalam masyarakat adat, perkawinan tidak hanya menjadi kepentingan orangorang yang bersangkutan, tetapi seluruh keluarga dan masyarakat adat juga ikut berkepentingan. Perkawinan harus merupakan perbuatan yang "terang," karena pelanggaran adat yang mungkin dilakukan oleh salah satu anggota, dapat mengganggu 
kebahagiaan hidup dan ketertiban seluruh keluarga dan masyarakat yang bersangkutan. Inilah sebabnya, kepala adat selalu turun tangan langsung dalam proses pelaksanaan perkawinan (Soewondo, 1984: 42).

Berbeda dengan Soewondo yang memposisikan perkawinan adat sebagai kepentingan keluarga yang bersangkutan dan masyarakat adat sekaligus, Iman Sudiyat memahami bahwa perkawinan adat adakalanya menjadi kepentingan persekutuan adat atau klan, dan bisa juga menjadi kepentingan pribadi, tergantung pada tata susunan masyarakat yang bersangkutan. Bagi kelompok yang menyatakan diri sebagai sebuah kesatuan, klan, kaum, kerabat misalnya, perkawinan merupakan sebuah sarana untuk melangsungkan hidup kelompoknya secara teratur, sarana yang dapat melahirkan generasi baru yang melanjutkan garis hidup kelompoknya. Perkawinan juga merupakan sarana untuk meneruskan garis keturunan keluarga dalam persekutuan tersebut (Sudiyat, 1981: 123).

Bagi kelompok yang tidak lagi terikat dalam persekutuan kerabat, perkawinan pada awalnya memang merupakan urusan keluarga, namun perlahan mereka melepaskan diri dan hanya meneruskan garis hidup orang tuanya. Shofwan menyatakan sulitnya memahami penjelasan Iman Sudiyat, khususnya pada bagian yang menyatakan perkawinan sebagai urusan pribadi dalam hukum adat, terlebih ia tidak memberikan contoh tentang hal ini. Sehingga dengan melihat dua pernyataan tentang perkawinan adat di atas, penulis lebih memilih untuk memposisikan perkawinan sebagai kepentingan keluarga dan suku sekaligus (Taufiq, 2010: 44).

Senada dengan pandangan ini, Hilman Hadikusuma mengemukakan bahwa menurut hukum adat pada umumnya di Indonesia, perkawinan bukan saja berarti sebagai perikatan Perdata, tetapi juga merupakan perikatan adat dan sekaligus perikatan kekerabatan dan ketetanggaan. Dengan kata lain, terjadinya suatu ikatan perkawinan bukan semata-mata membawa akibat terhadap hubungan keperdataan, seperti hak dan kewajiban suami isteri, harta bersama, kedudukan anak, hak dan kewajiban orang tua, tetapi juga menyangkut hubungan adat-istiadat, kewarisan, kekeluargaan, kekerabatan, ketetanggaan serta menyangkut upacara-upacara adat dan keagamaan (Hadikusuma, 1990: 8-10). Beberapa istilah perkawinan adat menurut Bewa Ragarino adalah sebagai berikut (Ragawino, 2008: 72-73).

1). Kawin lari. Kedua calon suami isteri bersama-sama melakukan perkawinan sendiri. Hal ini dimaksudkan untuk menghindari dari suatu keharusan misalnya membayar "jujur," atau orang tua tidak setuju dan menghindari dari prosedur yang berbelit-belit.

2). Perkawinan bawa lari. Seorang pemuda melarikan seorang gadis yang sudah ditunangkan atau seorang wanita yang sudah bersuami dan wanita itu dipaksa oleh pemuda tersebut. Jadi seolah-olah suatu penculikan.

3). Perkawinan "Nyalindung kegelung." Perkawinan seorang wanita kaya dengan pemuda miskin. 
4). Perkawinan "Manggi Kaya." Perkawinan antara seorang suami dengan isteri miskin.

5). Perkawinan "Ngarah gawe." Perkawinan antara sorang gadis yang belum dewasa dengan pemuda yang sudah dewasa. Setelah menikah suami yang sudah dewasa bertempat tinggal di rumah mertuanya, mereka belum dapat hidup sebagai suami isteri selama isteri belum dewasa.

6). Kawin "Gantung." Perkawinan yang dilaksanakan oleh kedua orang tua, sedangkan kedua mempelai sama-sama belum dewasa.

7). Perkawinan "Semendo Ambil Anak." Perkawinan agar menantu lakilaki itu menjadi anaknya sendiri.

Dalam pendekatan antropologi bahwa pada adat masyarakat Lampung dalam pelaksanaan perkawinan menggunakan sebuah kebiasaan lelarian, yaitu perempuan yang akan dinikahinya harus dibawa laki-laki pergi dari rumahnya dikarenakan hantaran atau seserahan yang harus dipenuhi pihak laki-laki kepada pihak perempuan berjumlah besar, sehingga pihak laki-laki tak mampu memenuhinya.

\section{Manfaat dan Dampak Seserahan Dalam Perkwaninan Masyarakat \\ Lampung}

Perkawinan merupakan jalan alami dan biologis yang paling baik dan sesuai untuk menyalurkan dan memuaskan naluri seks karena naluri seks merupakan naluri yang paling kuat yang selamanya menuntut adanya jalan keluar. Dengan kawin badan jadi segar, jiwa jadi tenang, mata terpelihara dari melihat yang haram dan perasaan tenang menikmati barang yang halal
(Ghozali, 2008: 69; Thalib, 1995: 34-36). Demikianlah hikmah dari perkawinan. Jika perkawinan ada hikmahnya, uang hantaran pun ada manfaatnya. Walaupun praktek pemberian uang hantaran mempunyai manfaat, tetapi tetap mempunyai dampak negatif. Di antara manfaat dan dampak negatif praktek uang hantaran adalah sebagai berikut.

1). Mempertahankan adat (Mustafa, 2018: 63). Ungkapan pepatah "biar mati anak jangan mati adat" menunjukkan betapa pentingnya adat dalam mengatur kehidupan masyarakat Lampung (Kasimin, 1989: 53). Sebagai suatu usaha untuk memastikan adat yang diwarisi secara turun-menurun tidak hilang ditelan zaman, masyarakat lampung tetap mempraktekkannya walaupun terkadang praktek tersebut memberikan beban kepada sebagian pihak. Dikarenakan itulah bagi sebagian masyarakat lampung, adat bukan hanya tradisi setempat, tetapi merupakan undang-undang yang perlu dipatuhi (Md, 2006: 162).

2). Menunjukkan keseriusan laki-laki yang ingin menikah. Keseriusan tidak hanya dapat digambarkan dengan lisan saja, tetapi keseriusan haruslah disertakan dengan perbuatan. Pemberian uang hantaran merupakan salah satu keseriusan yang nyata bahwa laki-laki tersebut ingin menikah dengan pasangannya. Praktek uang hantaran juga merupakan satu bukti bahwa laki- laki dapat menanggung hidup pasangannya sehingga memberikan kepercayaan kepada orang tua perempuan untuk melepaskan anak mereka dengan senang hati.

3). Mempersiapkan pasangan. Waktu yang digunakan oleh laki-laki untuk mengumpul uang hantaran adalah waktu 
yang terbaik yang boleh digunakan oleh pasangannya untuk mempersiapkan diri dari segi mentalmaupun kemampuan melakukan kerja rumah seperti memasak ataupun menyiapkan persiapan rumah sebelum pesta misalnya mengecat rumah.

4). Membantu ekonomi keluarga perempuan (Prawiro, 2013: 60).https://mailattachment.googleusercontent.com/attachmen t/u/0/?view=att\&th=169ff560e48eeb5c\&attid= $\underline{0.1 \& \text { disp }=\text { vah \& realattid }=169 f f 55 c 92133 d 49493}$ $1 \&$ safe=1\&zw\&saddbat=ANGjdJ912WhNRjKodYGQLVNK4g5j6c4CkrPfl8qxRQOEaSHI 4fRpKnHh4XyRjfQtrQZCgCYSHSIfkfh-

9Zaqsv8UKM8CLttfILWf46tKOxMYmxP6JpCdKsUBerV9FLJrkzxC2sr76bZjkonBkG dlOrrtDDABQfCB4f01KLv-x52hCFGqMObiNGCJeDZzqW1nlwmH5Sf2pTfmVCdhZSNh 7HBeph1vAKOIwSKGKUI8IsGyNsKzE53UGvOtL8 HFtOZo9N BbPGAK4zGW8M6H7FyIVxoeTAeg0 560AZ6wqjdYa1nk8rrbpPxGHXq6dCC9dAHtaP1 cYBGs0oDlwRvRb4MzpmdzjgE5bWkFZXCC06G3 0Gw3TSJ53o1n7awH3XHZXgyPHpj1s8F7iqnalq WD1BjjSdDoPXS9HbXP5d6xR0zZSu4etwwVGfzt DkRUt6yJZfHhzksDB6EUjOBJ6WZcZKdLlaE sQW aRQEZLtU6ISjfUM57blcsWxnredeYOLWDIJn1XYL 2x2ARTvMUgMdGtAOHEYmiVoxbUE2pO9JK70 WsGQEt Acj8nE-

AJclaX5WNxacZFxijXt6059RlyE9mBmMiJKEsnN9 Kpk6QSmPMKJBJwxylwDVveHF3iftdQAwODOU mBcfg8pREoRyx0VajTMILWJgoOlswug69Mh4d w - 0.1 footnote21 Pemberian uang hantaran sangat membantu keluarga perempuan dari segi ekonomi sesuai dengan tujuan diberikan, apa lagi jika perempuan tersebut adalah anak yatim. Terkadang uang tersebut dapat membiayai seluruh pesta pernikahan perempuan dan terkadang ada sisanya yang boleh digunakan oleh perempuan tergantung dengan jumlah yang disepakati.
5). Menambah motivasi dalam mencari atau melakukan kerja. Laki-laki akan berusaha dengan bersungguh-sungguh dalam mengumpul uang yang diperlukan untuk mendapatkan apa yang dihajati. Dengan motivasi nikah, laki-laki yang pemalas akan mencari kerja dan bagi lakilaki yang sudah mempunyai kerja berkemungkinan akan melakukan kerja sampingan serta lebih fokus dan semangat dalam melakukan kerja.

6). Mendidik diri berhemat. Latar belakang setiap orang yang berbeda-beda membuat adanya ketidak samaan dari segi ekonomi. Ada yang kaya dan ada yang kurang berkecukupan. Bagi laki-laki yang kaya tetapi boros akan mendidik mereka untuk berhemat dalam menggunakan uang sebagai upaya menabung dalam mengumpul uang hantaran.

\section{Dampak Tingginya Uang Seserahan atau Hantaran}

\section{1). Membebankan kepada laki-laki yang} kelas ekonominya menengah-ke-bawah (Mustafa, 2018: 64). Praktik uang hantaran memang tidak dinafikan bahwa membebankan laki-laki apalagi jika laki-laki tersebut memang dari keluarga yang sederhana ataupun pendapatan bulanannya hanya cukup untuk dirinya saja. Mempelai laki-laki bukan hanya perlu memberikan uang kepada pihak perempuan, malahan mereka juga harus mengeluarkan uang sendiri untuk pesta pernikahan mereka. Beban ini jelas terlihat apabila mereka terpaksa berhemat, melakukan kerja sampingan ataupun kerja lebih dalam mengumpul jumlah yang diperlukan.

2). Adat lebih diutamakan dari pada agama. Penetapan kadar mahar yang 
lebih rendah daripada uang hantaran menempatkan seolah-olah mahar tidak ada nilainya padahal mahar merupakan salah satu rukun perkawinan yang apabila tidak sempurna salah satu rukun maka tidak sahnya perkawinan tersebut. Sebaiknya uang hantaran disatukan ke dalam mahar dengan kata lain tidak ada uang hantaran dan yang ada hanyalah mahar untuk menunjukkan bahwa mahar lebih berjumlah dari uang hantaran.

3). Kawin lari. Keinginan yang tinggi untuk menikah tetapi terhalang disebabkan uang hantaran membuatkan lakilaki maupun pasangannya mencari jalan alternatif untuk membenarkan perkawinan sekalipun terpaksa membelakangkan keputusan dan mencoreng nama baik keluarga. Walaupun kawin lari bukanlah suatu perbuatan yang boleh dibanggakan tetapi lebih baik dari pada melakukan perzinaan yang sudah terlarang lagi nyata (Prawiro, 2013: 63).

4). Berhutangan. Siapa pun yang mempunyai masalah keuangan pasti akan meminta pertolongan. Cara termudah meminta tolong dalam masalah keuangan adalah dengan meminjam. Peminjaman uang boleh dilakukan dengan meminjam dari keluarga, kawan-kawan terdekat ataupun pihak bank. Apabila terjadi proses peminjaman maka terjadinya perutangan. Banyak kasus di mana setelah bernikah lakilaki terpaksa membayar utangnya sehingga membuat belanja perbulan keluarga terpaksa dikurangkan. Jika dilihat dari aspek agama, seandainya peminjaman dibuat dari bank sebenarnya hanya mengandung unsur riba di mana jika proses perkawinan berlangsung menggunakan uang tersebut maka tidak ada keberkatan di dalamnya.

5). Perzinaan. Salah satu hikmah perkawinan adalah dapat menyalurkan nafsu syahwat. Apabila terdapat suatu hal yang menghalang kepada melakukan perkawinan, secara tidak langsung hal tersebut telah menghalang manusia dalam melepaskan syahwatnya melalui prosedur yang benar. Tingginya uang hantaran merupakan salah satu penyebab kepada perzinaan di waktu laki-laki tidak mampu menyediakan uang hantaran dan nafsu untuk melakukan hubungan suami istri tidak lagi dapat ditahan (Q.S. Al-Israa' 17: 32).

6). Penggadaian atau penjualan barang berharga. Di saat desakan waktu dalam mengejar sesuatu, tidak ada yang mustahil akan dilakukan sekalipun terpaksa melepaskan barang yang paling disayangi ataupun menggadaikannya untuk mendapatkan sesuatu yang lebih berjumlah. Sama halnya di dalam mengumpulkan uang hantaran. Laki-laki yang ingin memperistrikan perempuan yang disukainya akan memilih untuk menjual apa saja yang dia miliki ataupun menggadaikannya sekalipun barang tersebut mempunyai maksud dan nilai tersendiri bagi si laki-laki.

7). Penundaan pernikahan. Pernikahan akan ditunda apabila uang yang diminta oleh orang tua perempuan tidak dapat disediakan pada waktunya. Kebiasaannya orang tua perempuan akan memberikan waktu kepada pihak laki-laki untuk mengumpulkan jumlah yang diminta. Jangka waktu yang diberi berdasarkan ketentuan orang tua perempuan ataupun kesepakatan kedua belah pihak. Seandainya pihak laki-laki tidak dapat menyediakan 
uang setelah tiba masa yang dijanjikan, besar kemungkinan akan terjadinya pembatalan nikah ataupun penambahan waktu sekiranya diberi izin oleh orang tua perempuan.

8). Pembatalan nikah. Banyak orang banyak ragamnya. Tidak semua orang tua perempuan yang sanggup melihat anaknya terlambat menikah dan tidak semua laki-laki sanggup memberikan apa yang dia tidak miliki walaupun bisa dicapai jika disertakan dengan usaha. Sekalipun laki-laki sudah berusaha untuk mengumpul jumlah yang diminta, dikarenakan keterbatasan dalam banyak hal, kemungkinan untuk tidak dapat memenuhinya juga ada. Rasa cinta dan sayang terpaksa dikorbankan apabila uang menjadi penunjang utama dalam mendirikan perkawinan.

9). Anak gadis tua (Kamsah dan Omar, 2007: 69). Penetapan uang hantaran yang dipengaruhi oleh pendidikan dan pekerjaan membuat sebagian perempuan yang sukses dalam hidupnya menjadi anak gadis tua. Kesuksesan yang seharusnya dibanggakan ibarat menjadi mimpi ngeri apabila tidak ada atau kurang laki-laki yang berani untuk mendekati karena takut akan jumlah uang hantaran yang terlalu tinggi terhadapnya.

10). Pihak laki-laki tidak melangsungkan pesta pernikahan. Uang yang telah banyak dihabiskan kepada pihak perempuan membuat mempelai laki-laki tidak melangsungkan pesta pernikahan bagi pihaknya dan terdapat juga mempelai lakilaki yang membuat pesta pernikahan hanya sekadar memberi makan kue kepada tamunya berbeda dengan kebiasaan dilakukan, yaitu dengan menjamu nasi.

\section{Simpulan}

Praktek uang Seserahan atau hantaran merupakan suatu praktek yang dilakukan oleh masyarakat adat Lampung. Penetapan jumlah uang seserahan dalam masyarakat adat Lampung ditetapkan dengan melihat kepada pendidikan, pekerjaan perempuan dan kebiasaan jumlah yang ditetapkan di kampung adat di Lampung. Penetapan jumlah dan waktu uang hantaran diberikan ditentukan dengan cara kesepakatan dari kedua belah pihak, tetapi tetap saja keputusannya dari pihak perempuan. Pihak laki-laki akan meminta jumlah uang hantaran dikurangi seandainya tidak ada kemampuan untuk memenuhinya. Praktek pemberian uang hantaran membebankan mempelai laki-laki yang kelas ekonominya menengah-ke-bawah dan yang mempunyai berbagai tanggungan sehingga berakibatkan penundaan perkawinan dan berbagai kasus lainya, namun pengaruh tingginya uang Seserahan atau hantaran terhadap penundaan perkawinan ini, penulis dapat memberikan saran sebagai berikut:

1). Uang hantaran sebaiknya ditetapkan pada jumlah yang lebih rendah supaya tidak ada penundaan perkawinan yang terjadi dan seandainya pihak perempuan masih saja mau agar uang hantaran diberikan, sebaiknya hal itu dimasukkan ke dalam mahar. Hal ini akan membuat tidak ada uang hantaran dan yang ada hanyalah mahar saja.

2). Tokoh Adat harus mengkaji ulang jumlah uang hantaran dari segi penetapannya dengan menetapkan maksimal jumlah yang paling tinggi sebagaimana kerajaan menetapkan jumlah mahar yang 
paling minimal dan laki-laki haruslah hemat dalam kebutuhan dan mulailah menabung dari awal agar tidak ada kesulitan di masa yang akan datang serta orang tua mempelai perempuan sebaiknya memperhatikan gaji perbulan calon mempelai laki-laki dan tanggungannya sebelum menetapkan jumlah uang hantaran

3). Sebaiknya jumlah uang hantaran lebih rendah dari mahar untuk memperlihatkan bahwa agama lebih diutamakan dari pada adat dan laki-laki seharusnya melihat kafa'ah yang berarti serupa, sama, seimbang atau serasi agar penetapan jumlah uang hantaran tidak akan memberatkannya.

\section{Daftar Pustaka}

Abbas, Ahmad Sudirman. 2004. Qawaid Fiqhiyyah dalam Perspektif Islam. Jakarta: Pedoman Ilmu Jaya.

Agustino, Leo. 2011. Sisi Gelap Otonomi Daerah: Sisi Gelap Desentralisasi di Indonesia

Berbanding Era Sentralisasi. Bandung: Widya Padjadjaran.

Ali, Achmad. 2009. Menguak Teori Hukum (Legal Theory) dan Teori Peradilan (Judicial Prudence). Jakarta: Kencana.

Al-Qur'an. Surat Al-Israa' (17): 32.

Anderson, James. 1979. Public Policy-Making. Second edition. New York: Holt, Rinehart and Winston.

Angkupi, Prima. 2015. "Formulasi Perkawinan Adat Lampung dalam Bentuk Peraturan Daerah dan Relevansinya terhadap Hak Azasi Manusia, Jurnal Ilmu Syari'ah dan Hukum, Vol. 49, No. 2, Desember.
Bentham, Jeremy. 2006. Teori Perundang Undangan. terj. Nurhadi. Bandung: Penerbit Nusa Media.

Ghaffar, Ahmad Muhammad Abdul. 2005. Pengurusan Harta. Kuala Lumpur: Pustaka Syuhada.

Ghozali, Abdul Rahman.2008. Fiqh Munakahat, Cet. Ke-3. Jakarta: Kencana.

Hadikusuma, Hilman. 1990. Hukum Perkawinan Indonesia. Bandung: Mandar Maju.

Hazairin, April. 1975. "Tinjauan Mengenai UU Perkawinan Nomor 1 Th 1974." Lentera Hukum. Vol I (1). Jakarta: Tintamas.

Jafizham, T. 2010. Persintuhan Hukum di Indonesia dengan Hukumk Perkawinan Islam. Cet. Ke-3. Jakarta: PT Mestika.

Kamsah, Mohd. Fadzilah dan Noralina Omar. 2007. Soal Jawab Praperkahwinan. Kuala Lumpur: PTS Millennia.

Kasimin, Amran. 1989. Istiadat Perkahwinan Melayu: Satu Kajian Perbandingan. Kuala Lumpur: Dewan Bahasa dan Pustaka, Kementerian Pendidikan, Malaysia.

Kebudayaan, Departemen Pendidikan dan. 1990. Kamus Besar Bahasa Indonesia. Cet.Ke-3. Jakarta: Balai Pustaka.

Khallaf, Abdul Wahhab. 1994. Ilmu Ushul Fiqh. terjemahan Zuhri dan Ahmad Qarib. Semarang: Toha Putra Group.

Md, Mohd. Salleh Haji. 2006. NilaiNilai Adat dan Budaya dalam Amal Ibadat Masyarakat Melayu. Kuala Lumpur: Universitas Malaya. 
Mudjib, Abdul. 2001. Kaidah-kaidah

Ilmu Fiqih. Cet. Ke-2. Jakarta: Kalam Mulia.

Muhammad, Abu Abdullah bin Yazid bin Abdullah bin Majah Al Quzwaini.1952.Sunan Ibnu Majah. Riyadh: Darussalam.

Muhammad, Ahmad bin bin Hanbal. 1995. Musnad Ahmad bin Muhammad bin Hanbal. Juz Ke 3. Kaherah: Darul Hadis.

Mustafa, Muhammad Azhaa bin Haji. 2018. "Uang Hantaran dalam Adat Perkawinan Menurut Hukum Islam." Skripsi. Banda Aceh: Universitas Islam Negeri Ar-Raniry.

Pasal 16. 2008. "Perda Nomor 2 Tahun 2008 tentang Pemeliharaan Kebudayaan Lampung, Adat Budaya Lampung yang Berkenaan dengan Perkawinan Adat, Keberadaannya Wajib Dijaga, Dipelihara dan Dikembangkan (Pasal 16).

Pesponoto, K.Ng. Soebekti. 2013. Asas-Asas Dan Susunan Hukum Adat. Jakarta: Balai Pustaka.

Prawiro, Dimas. 2013.

"Implementasi Penetapan Uang Hantaran Nikah dalam Perspektif Hukum Islam." Skripsi. Riau: Universitas Islam Negeri Sultan Syarif Kasim.

Ragawino, Bewa. 2008. Pengantar dan Asas-Asas Hukum Adat Indonesia. Bandung: Fakultas Ilmu Sosial dan Ilmu Politik, Universitas Padjadjaran.

Saputra, Lucky Irwan. 2010. "Adat Larian di Provinsi Lampung." Skripsi. Jakarta: FISIP Universitas Indonesia.

Soewondo, Nani. 1984. Kedudukan

Wanita Indonesia dalam Hukum dan Masyarakat. Jakarta: Ghalia Indonesia.
Sudiyat, Imam. 1981. Hukum Adat

Sketsa Azas. Yogyakarta: Liberty.

Sulaiman,Abu Daud. 2009.Sunan Abi

Daud. Juz Ke-3. Beirut: Al-Risalah Al-A'limiah. Syarifuddin, Amir. 2008. Ushul Fiqh

2. Cet. Ke-4. Jakarta: Prenada Media Group.

Taufiq, M. Shofwan. 2010. "Perkawinan Non-Adat di kalangan Masyarakat Lampung Keratuan Melinting." Tesis. Yogyakarta: UIN Sunan Kalijaga.

Thalib, M. 1995. 40 Petunjuk Menuju Perkawinan Islami. Bandung: Irsyad Baitus Salam.

Thontowi, Jawahir, Irfan Nur Rachman, Nuzul Qur'aini Mardiya, Titis Anindyajati. 2012. Aktualisasi Masyarakat Hukum Adat (MHA): Perspektif Hukum dan Keadilan Terkait Dengan Status MHA dan Hak-hak Konstitusionalnya. Pusat Penelitian dan Pengkajian Perkara, Pengelolaan Teknologi Informasi dan Komunikasi Mahkamah Konstitusi Republik Indonesia, 